
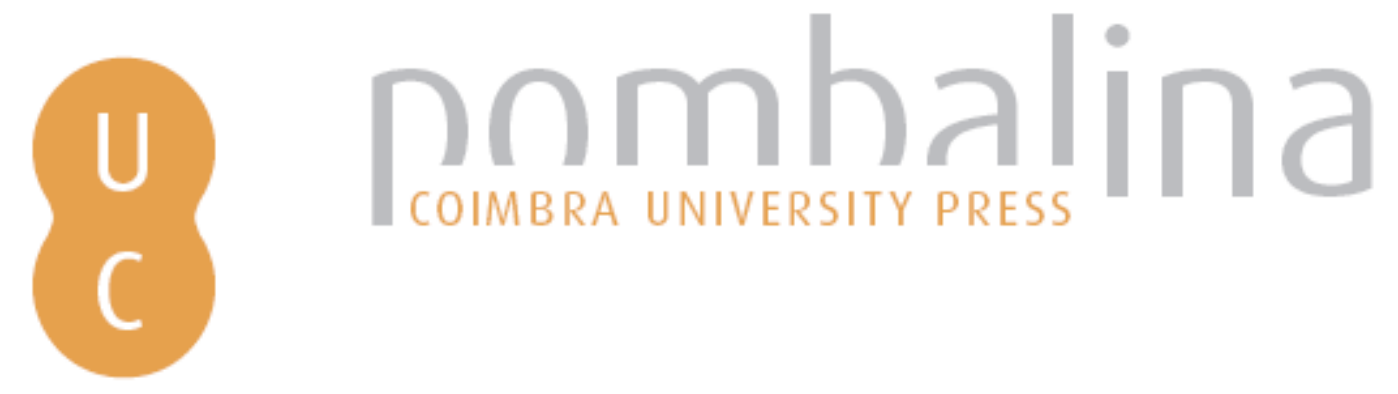

\title{
Requintar as refeições na primeira metade do século XIX: as louças do tenente- general Luís Inácio Xavier Palmeirim
}

\author{
Autor(es): $\quad$ Sousa, Gonçalo de Vasconcelos e \\ Publicado por: Imprensa da Universidade de Coimbra; Annablume \\ URL \\ persistente: URI:http://hdl.handle.net/10316.2/39663 \\ DOI: $\quad$ DOI:https://doi.org/10.14195/978-989-26-1191-4_34 \\ Accessed : $\quad$ 26-Apr-2023 08:22:50
}

A navegação consulta e descarregamento dos títulos inseridos nas Bibliotecas Digitais UC Digitalis, UC Pombalina e UC Impactum, pressupõem a aceitação plena e sem reservas dos Termos e Condições de Uso destas Bibliotecas Digitais, disponíveis em https://digitalis.uc.pt/pt-pt/termos.

Conforme exposto nos referidos Termos e Condições de Uso, o descarregamento de títulos de acesso restrito requer uma licença válida de autorização devendo o utilizador aceder ao(s) documento(s) a partir de um endereço de IP da instituição detentora da supramencionada licença.

Ao utilizador é apenas permitido o descarregamento para uso pessoal, pelo que o emprego do(s) título(s) descarregado(s) para outro fim, designadamente comercial, carece de autorização do respetivo autor ou editor da obra.

Na medida em que todas as obras da UC Digitalis se encontram protegidas pelo Código do Direito de Autor e Direitos Conexos e demais legislação aplicável, toda a cópia, parcial ou total, deste documento, nos casos em que é legalmente admitida, deverá conter ou fazer-se acompanhar por este aviso.

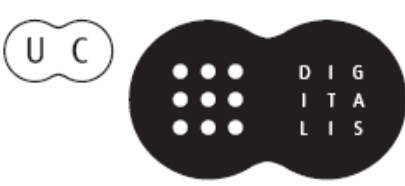




\title{
REQUiNTAR AS REFEIÇÕES NA PRIMEIRA METAde do SÉCULO XIX: AS LOUÇAS DO TENENTE-GENERAL Luís Inácio Xavier Palmeirim Over-refining meals in the first half of the nineteenth century: the ceramics of Lieutenant General Luis Inácio Xavier Palmeirim
}

\author{
Gonçalo de Vasconcelos e Sousa ${ }^{1}$ \\ Universidade Católica Portuguesa, Escola das Artes \\ CITAR - Centro de Investigação em Ciência \\ e Tecnologia das Artes (EA-UCP) \\ gsousa@porto.ucp.pt
}

\begin{abstract}
Resumo: A relevância das porcelanas e de outras cerâmicas enquanto símbolo de estatuto social surge acompanhada pela posse de objectos de prataria e de vidros, enquadrando-se num contexto de refinamento de gestos e atitudes, facto que a sociedade oitocentista vivenciou com particular intensidade. Entre 1815 e 1817, o tenente-general Luís Inácio Xavier Palmeirim adquiriu um conjunto de aparelhos de mesa de jantar, cujo conhecimento nos é dado através de documentos minuciosos do seu arquivo. Neste contexto, salienta-se a encomenda em Macau de um serviço de mesa com várias centenas de peças, efectuada a partir do Rio de Janeiro. Realizada em duas fases, esta aquisição surge acompanhada por pormenores formais e decorativos das porcelanas, que a transformam numa fonte importante para o conhecimento do mercado asiático de bens de luxo neste primeiro quartel do século XIX.

Palavras-chave: Porcelana; cerâmica; século XIX; tenente-general Palmeirim; Macau; Rio de Janeiro
\end{abstract}

Aвstract: The relevance of porcelain and other ceramics as a social status symbol appears accompanied by the possession of silver objects and glass, framing it in a context of refinement of gestures and attitudes, which the nineteenth-century society experienced with particular intensity. Between 1815 and 1817, Lieutenant General Luís Inácio Xavier Palmeirim acquired a set of dining table sets, knowledge of which is provided through detailed records in his archive. In this context, we emphasize the order for a table service with several hundred pieces, made in Macao from Rio de Janeiro. Carried out in two phases, this acquisition is accompanied by formal and decorative details of porcelain, which transform it into an important

${ }^{1}$ Universidade Católica Portuguesa, Escola das Artes; investigador integrado do CITAR - Centro de Investigação em Ciência e Tecnologia das Artes (EA-UCP). O Autor agradece a Ricardo Charters de Azevedo e a Lourenço Correia de Matos as referências biográficas do tenente-general que simpaticamente lhe forneceram. Às descendentes do tenente-general Palmeirim, D. Ana e D. Teresa Palmeirim, agradeço as informações e a cedência de iconografia sobre este militar. 
source for the knowledge of the Asian market for luxury goods in the first quarter of the nineteenth century.

KeY-Words: Porcelain; ceramics; XIXth century; lieutenant general Palmeirim; Macau; Rio de Janeiro

\section{INTRODUÇÃo}

O serviço dos alimentos, sobretudo em momentos especiais, adquiria um grande requinte através do recurso a uma vasta diversidade tipológica de peças cerâmicas, de que as elites se rodeavam para refinar as suas festas, saraus e outras recepções mais restritas. Aparelhos de mesa, serviços de chá, café e chocolate, quando não peças soltas, iam sendo comprados (ou ofertados) de forma a cumprirem essa missão.

Na primeira metade do século XIX, a porcelana chinesa manteve a sua relevância, no panorama português dos objectos móveis, encontrando-se em plena voga na alimentação das elites já desde a segunda metade de Setecentos. Este movimento foi acompanhado pela aquisição de serviços ingleses de pó de pedra, com motivos decorativos variados, que haviam conquistado os estamentos sociais elevados em Portugal desde esse período do século das Luzes.

A primeira metade do século XIX reforça tal vontade aquisitiva, a par com a busca de peças francesas, e a análise da documentação de arquivos particulares e de inventários orfanológicos espelha tal empenho de consumo, relevando, se bem que por vezes com descrições pouco pormenorizadas, as referências à sua presença nas casas nobres do País. No entanto, diga-se em abono da verdade, a investigação em Portugal, neste domínio, surge, ainda, de forma muito incipiente, havendo que calcorrear muita documentação em diversas zonas de Portugal (continental, insular e, ainda, Brasil) para se alcançar uma perspectiva mais apurada.

Testemunho dessa utilização revela-se a compra de vários aparelhos de mesa de cerâmica pelo tenente-general Luís Inácio Xavier Palmeirim $(1765-1839)^{2}$ (fig. 1), designadamente um serviço de pó de pedra inglês (quadro I), um de cerâmica azul e branca, provavelmente de porcelana chinesa azul e branca (quadros II) e outro de porcelana chinesa (quadros III e IV). Esta última, a mais relevante, é efectuada pelo militar em Macau, a partir do Rio de Janeiro, no ano de 1817, reforçada, posteriormente, com novas aquisições em 1820, e de que documentos do seu arquivo particular fornecem pormenorizadas indicações. Outros testemunhos deste acervo mostram, também, a posse de diversos vidros e objectos de ourivesaria, de

\footnotetext{
${ }^{2}$ Datas referenciadas in Baena, 1882: 16-17.
} 
Requintar as refeições na primeira metade do século XIX: as louças do tenente-general Luís Inácio Xavier Palmeirim

cuja gestão e inventário se vai ocupando em diversas datas, até perto da sua morte, ocorrida nos finais da década de 30 de 1800 .

Quadro I - Serviço de louça inglesa branca com cercadura escarlate que comprei em Maio de 1815 por $66 \$ 000$ rs. metal, da que existe e se tem quebrado até ao dia de hoje 1 de Janeiro de 1827

\begin{tabular}{|c|c|c|c|c|}
\hline Designações & Constava & $\begin{array}{c}\text { Tem-se } \\
\text { quebrado }\end{array}$ & Consertadas & Existe \\
\hline Terrinas para sopa & 5 & 1 & 0 & 4 \\
\hline Tampas das ditas & 5 & 1 & 0 & 4 \\
\hline Pratos das ditas & 5 & 1 & 0 & 4 \\
\hline Pratos travessas rombos da $1 .^{\mathrm{a}}$ ordem & 4 & 1 & 0 & 3 \\
\hline Ditos... da $2 .^{\text {a }}$ & 4 & 1 & 0 & 3 \\
\hline Ditos... da $3 .^{a}$ & 4 & 1 & 0 & 3 \\
\hline Ditos... da $4 .^{\mathrm{a}}$ & 6 & 1 & 0 & 5 \\
\hline Ditos... da $5 .^{a}$ & 4 & 0 & 0 & 4 \\
\hline Ditos... da $6 .^{\mathrm{a}}$ & 4 & 1 & 0 & 3 \\
\hline Ditos... da $7 .^{\mathrm{a}}$ & 6 & 0 & 0 & 6 \\
\hline Ditos... da $8 .^{a}$ & 4 & 2 & 0 & 2 \\
\hline Ditos... da 9. ${ }^{\mathrm{a}}$ & 6 & 1 & 0 & 5 \\
\hline Ditos ovais da $1 .^{\text {a }}$ Ordem & 2 & 0 & 1 & 1 \\
\hline Ditos... da 2.a dita & 1 & 0 & 0 & 1 \\
\hline Ditos sopeiros & 53 & 5 & 0 & 48 \\
\hline Ditos de guardanapo & 144 & 21 & 0 & 123 \\
\hline Ditos de sobremesa & 56 & 12 & 1 & 43 \\
\hline Ditos para doce & 23 & 1 & 0 & 22 \\
\hline Terrinas para caldo & 8 & 1 & 0 & 7 \\
\hline Tampas das ditas & 8 & 1 & 0 & 7 \\
\hline Pratinhos das ditas & 8 & 1 & 0 & 7 \\
\hline Colheres para molho & 13 & 0 & 0 & 13 \\
\hline Pratos quadrados & 11 & 4 & 0 & 7 \\
\hline Tampas dos ditos & 11 & 5 & 0 & 6 \\
\hline Saleiros & 3 & 1 & 0 & 2 \\
\hline Pratinho para conserva & 2 & 0 & 0 & 2 \\
\hline Prato para peixe & 1 & 1 & 0 & 0 \\
\hline Ralo para prato de peixe & 1 & 0 & 0 & 1 \\
\hline Pés para o prato do peixe & 2 & 0 & 0 & 2 \\
\hline Saladeira & 1 & 0 & 0 & 1 \\
\hline \multirow[t]{2}{*}{ Prato redondo com pé, para pudim } & 1 & 0 & 0 & 1 \\
\hline & 406 & 64 & 2 & 340 \\
\hline
\end{tabular}

Fonte: Arquivo Particular, Dossier Palmeirim. 
Gonçalo de Vasconcelos e Sousa

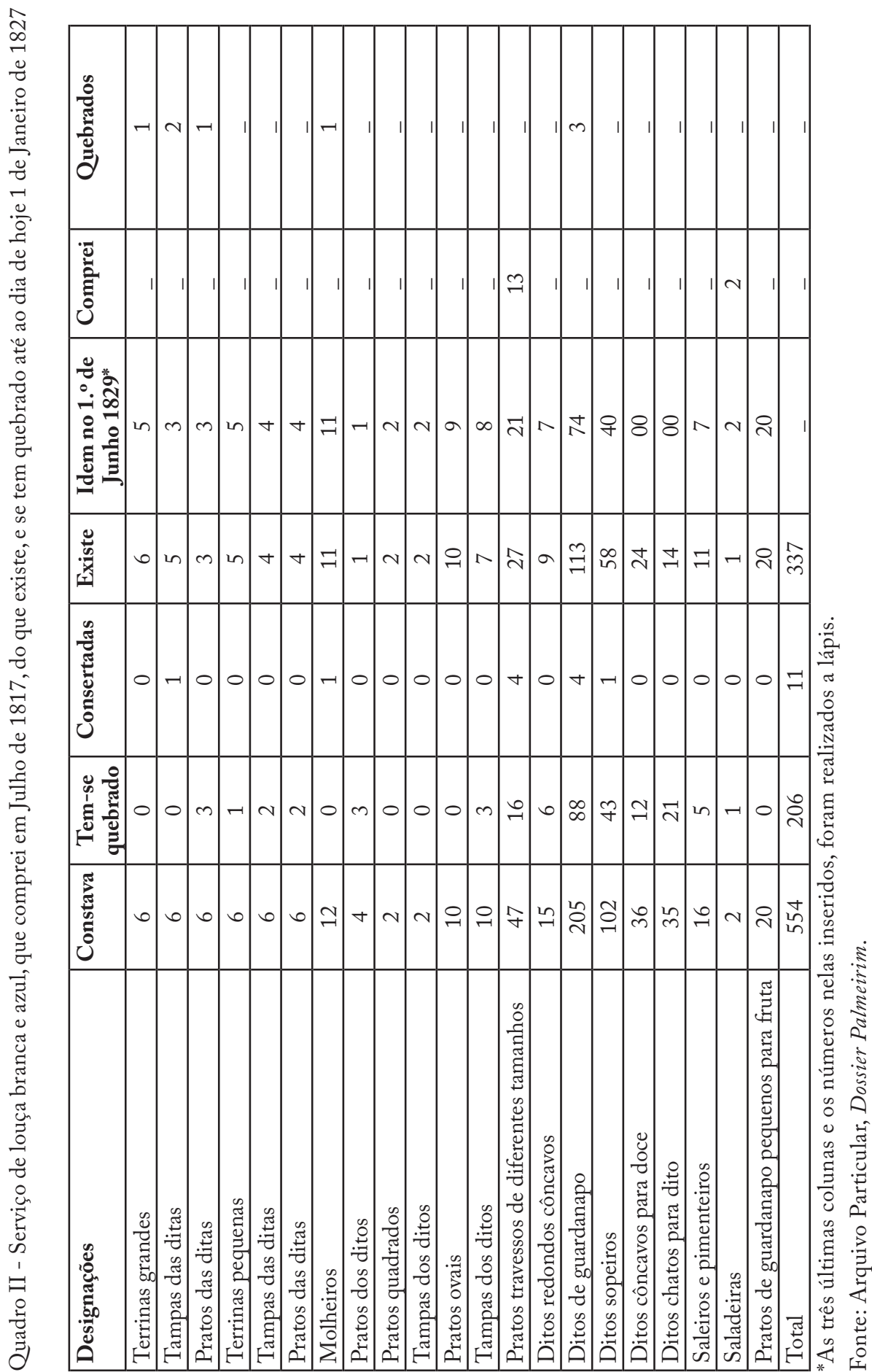


Requintar as refeições na primeira metade do século XIX: as louças do tenente-general Luís Inácio Xavier Palmeirim

Quadro III - Serviço de louça fina da China, branca com cercadura verde e ouro, que mandei vir de Macau no primeiro de Outubro de 1819, o qual custou 503\$640 réis metal, cujo serviço aumentei com outras peças vindas também de Macau em 1822 as quais custaram $29 \$ 100$ rs., fazendo o total serviço a soma de 532\$740 réis, o que do mesmo existe, e do que se tem quebrado "sem ter servido" até ao primeiro de Janeiro de 1827

\begin{tabular}{|c|c|c|c|c|}
\hline Nomes & Consta-va & $\begin{array}{c}\text { Tem-se } \\
\text { quebrado }\end{array}$ & Consertadas & Existe \\
\hline Terrinas grandes para sopa & 3 & 0 & 0 & 3 \\
\hline Tampas das ditas & 3 & 0 & 0 & 3 \\
\hline Pratos das ditas & 3 & 0 & 0 & 3 \\
\hline Terrinas pequenas para caldo & 4 & 0 & 0 & 4 \\
\hline Tampas das ditas & 4 & 0 & 0 & 4 \\
\hline Pratos das ditas & 4 & 0 & 0 & 4 \\
\hline Pratos quadrados de 10 polegadas & 4 & 0 & 0 & 4 \\
\hline Tampas dos ditos & 4 & 0 & 0 & 4 \\
\hline Pratos redondos para pudim & 5 & 2 & 0 & 3 \\
\hline Pratos fundos e com ralos para peixe & 2 & 0 & 0 & 2 \\
\hline $\begin{array}{l}\text { Cinco jogos de pratos travessos de cinco } \\
\text { pratos cada jogo }\end{array}$ & 25 & 0 & 0 & 25 \\
\hline Pratos de 20 polegadas para leitões & 3 & 0 & 0 & 3 \\
\hline Saladeiras & 2 & 1 & 0 & 1 \\
\hline Cestos para fruta & 12 & 2 & 0 & 10 \\
\hline Pratos arrendados dos ditos & 12 & 4 & 1 & 7 \\
\hline Manteigueiras & 4 & 3 & 0 & 1 \\
\hline Tampas das ditas & 4 & 1 & 0 & 3 \\
\hline Pratos das ditas & 4 & 0 & 0 & 4 \\
\hline Saleiros & 4 & 0 & 0 & 4 \\
\hline Pratos sopeiros & 36 & 7 & 0 & 29 \\
\hline Ditos de guardanapo & 96 & 19 & 4 & 73 \\
\hline Ditos de sobremesa de 8 polegadas & 48 & 7 & 1 & 40 \\
\hline Ditos de ................... 7 ditas & 36 & 4 & 0 & 32 \\
\hline Ditos côncavos de........ 6 ditas & 6 & 0 & 0 & 6 \\
\hline Tigelas para caldo & 12 & 0 & 0 & 12 \\
\hline Tampas das ditas & 12 & 0 & 0 & 12 \\
\hline \multirow[t]{2}{*}{ Pratos das ditas } & 12 & 5 & 0 & 7 \\
\hline & 364 & 55 & 6 & 303 \\
\hline
\end{tabular}

Fonte: Arquivo Particular, Dossier Palmeirim. 
Quadro IV - Factura de peças que faltam ao aparelho de mesa que Sebastião Lopes Ramos trouxe de Macau ao Tenente-General Luís Inácio Xavier Palmeirim (Rio de Janeiro, 12 de Fevereiro 1820)

\begin{tabular}{|l|c|}
\hline Descrição & Quantidade \\
\hline Pratos redondos para tortas, pudins e outras massas & $3^{* *}$ \\
\hline De quinze polegadas de diâmetro & 3 \\
\hline Ditos de treze ditas & 3 \\
\hline Ditos de onze ditas & 12 \\
\hline Tigelas com pratos para caldo & 8 \\
\hline Cestos à inglesa para fruta & $1^{* *}$ \\
\hline Prato para amostra* & - \\
\hline $\begin{array}{l}\text { Toda esta louça deve ter cercadura de verde, e ouro, e a marca conforme o } \\
\text { prato que se remete pertencente ao aparelho acima mencionado, o qual deverá } \\
\text { tornar, e quando aconteça quebrar-se, vir outro em seu lugar }\end{array}$ \\
\hline
\end{tabular}

* Noutra letra.

** Faltaram.

Fonte: Arquivo Particular, Dossier Palmeirim.

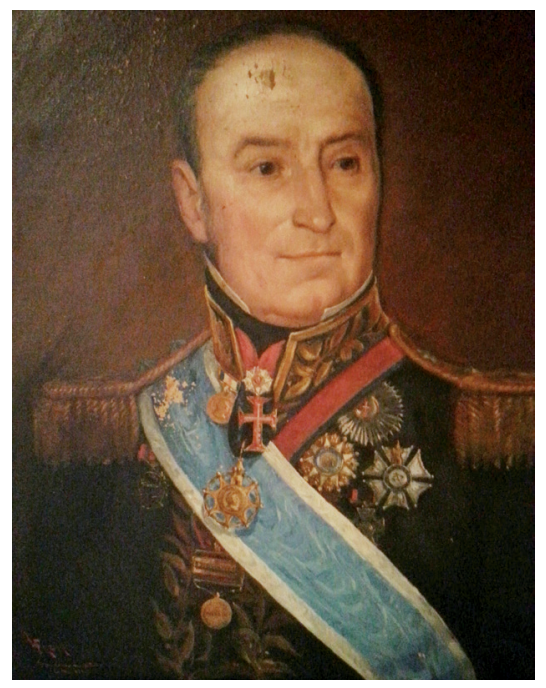

Figura 1 - Retrato do Luís Inácio Xavier Palmeirim, pelo pintor José Joaquim Primavera. Colecção de D. Teresa Palmeirim.

O propósito deste estudo centra-se, a partir de um caso concreto, em demonstrar as preocupações com o requinte cerâmico no serviço dos alimentos e das bebidas da primeira metade de Oitocentos, atendendo, sobretudo, aos grandes serviços de mesa do militar em estudo. Se bem que não seja alvo da referência específica neste trabalho, não podemos esquecer a complexidade de 
Requintar as refeições na primeira metade do século XIX: as louças do tenente-general Luís Inácio Xavier Palmeirim

elementos que intervêm na mesa, e que passam pela prataria ${ }^{3}$ utilizada no serviço dos alimentos e da decoração, os vidros e cristais, bem como os têxteis para a decoração e uso da mesa, como toalhas e guardanapos. Tudo isto acompanhado pela relevância crescente dos manuais de etiqueta, de que, para Oitocentos, referenciaríamos D. João de Nossa Senhora da Porta Sequeira (fig. 2), J. I. Roquette (fig. 3) ou, mais no final da centúria, Maria Amália Vaz de Carvalho.

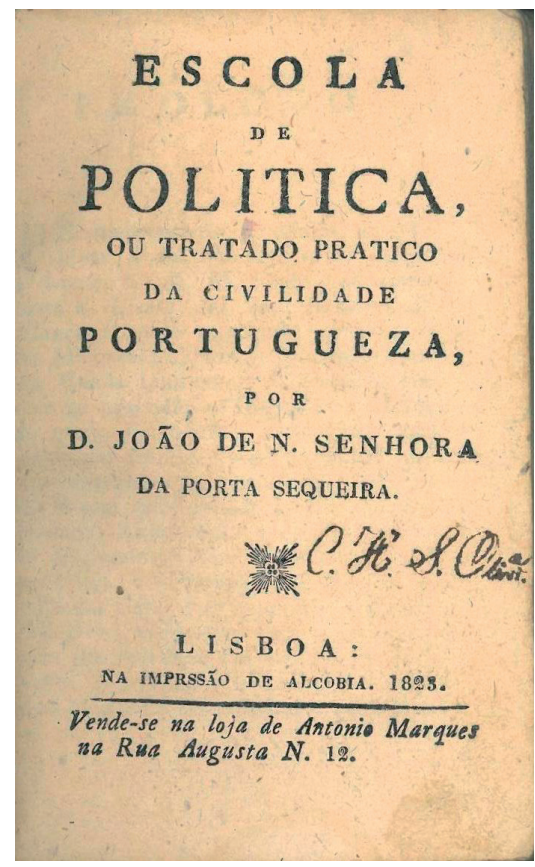

2 - Fac-símile do frontispício do livro "Escola de Política, ou Tratado Pratico da Civilidade Portugueza”, de D. João de Nossa Senhora da Porta Sequeira (1823).

${ }^{3}$ Luís Inácio Xavier Palmeirim possuía, para acompanhar a variedade das suas louças, diversas peças de prataria, como um bule para chá com balde no bico, uma cafeteira, leiteira, açucareiro, taça de lavar xícaras - mais conhecida como taça de pingos -, frasco de chá. Acompanhavam-nos os imprescindíveis talheres, espraiando-se entre facas e garfos de trinchar, colheres para tirar sopa e outras para arroz, as facas, garfos e colheres habituais, mas também garfos, colheres e facas de sobremesa. Para o chá, as indispensáveis colheres, havendo duas de açucareiro. Complementava os domínios do serviço relacionado com os alimentos a presença de dois paliteiros, não tendo sido registadas as respectivas tipologias. A referência a cinco salvas para o serviço de um a cinco copos reforça a indicação de que esta tipologia se destinava a esse fim, tal como já encontrámos noutras distintas fontes. Vd., para os objectos argênteos de Palmeirim, Arquivo Particular, Dossier Palmeirim, "Relação da prata e ouro que tenho". 
Gonçalo de Vasconcelos e Sousa

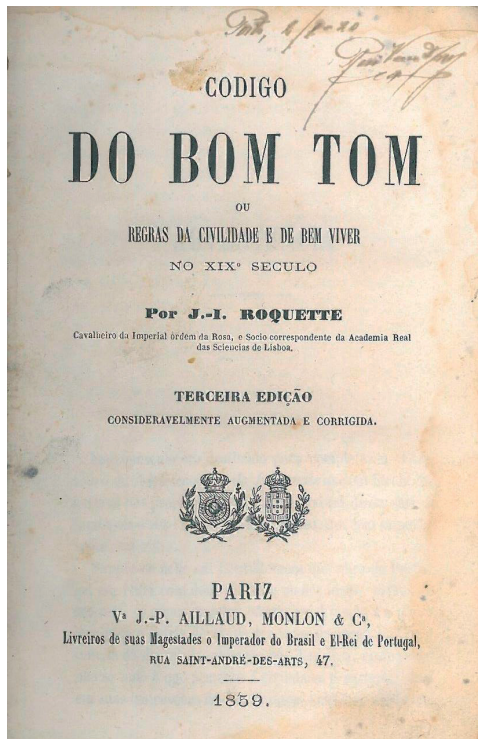

3 - Fac-símile do frontispício do livro "Código de Bom Tom ou Regras da Civilidade e de Bem Viver no XIX. ${ }^{\circ}$ Século”, 3. a ed., de J.-I. Roquette (1859).

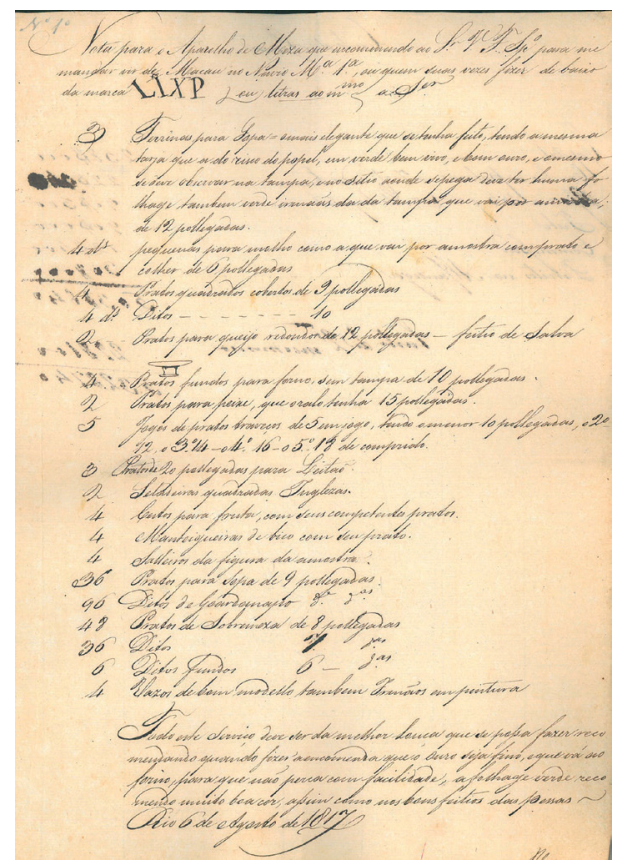

4 - Fac-símile do documento com as especificações da encomenda do serviço de porcelana chinesa para Macau em 1817. Arquivo Particular, Dossier Palmeirim. 


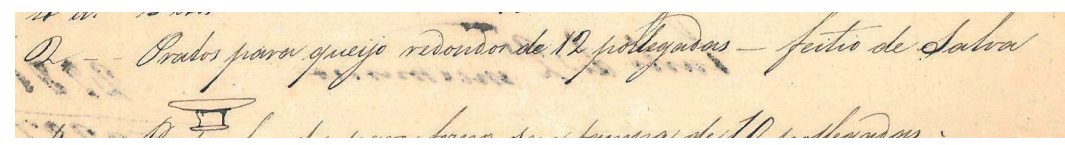

5 - Pormenor do desenho de salva de pé, cujo desenho seguiu para Macau de forma a executarem pratos redondos para queijo.

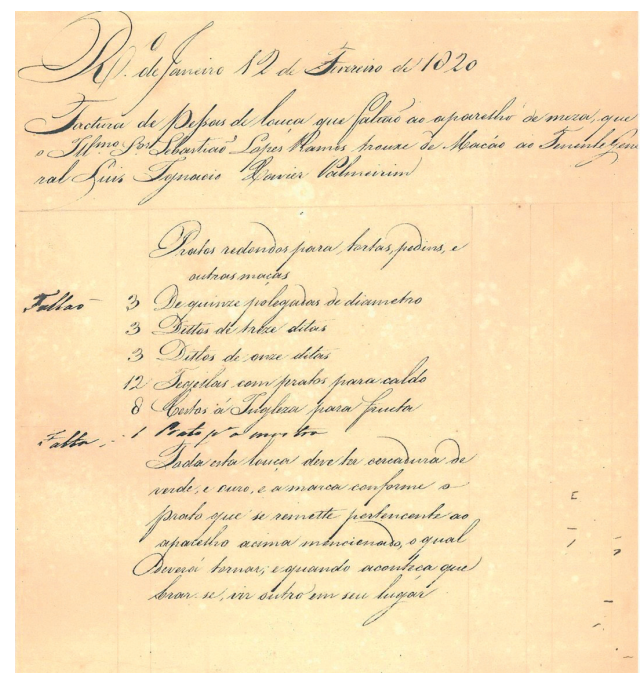

6 - Fac-símile do documento com as especificações do reforço da encomenda de mais algumas peças para o serviço de porcelana chinesa, para Macau, em 1820. Arquivo Particular, Dossier Palmeirim.

\section{Enquadramento}

O estudo do Rio de Janeiro durante o período da estância da corte brigantina, entre 1808 e 1822, e as relações com o Oriente, em termos da afluência dos bens de consumo destinados à decoração e à utilização pelas elites, no fundo, o comércio de objectos de luxo, encontra-se ainda por apurar com precisão, o que implica um levantamento dos registos alfandegários existentes na cidade nesse tempo, para além da análise de outras fontes que possam precisar a dimensão dessas ligações.

Anos atrás, Maria João Petisca apresentou, na tese de mestrado defendida na Escola das Artes da Universidade Católica Portuguesa e intitulada A laca de Cantão: um estudo sobre biombos chineses de exportação nos séculos XVIII e XIX $X^{4}$, um biombo com as armas do 7. ${ }^{\circ}$ conde da Ribeira Grande,

\footnotetext{
${ }^{4}$ Petisca 2009: 91-97; vd., ainda, Petisca 2010: 89 e 94 (fig. 12).
} 
D. José Maria Gonçalves Zarco da Câmara, cuja figuração surge repetida nas suas distintas folhas. A este propósito, podemos levantar a questão da relevância do Rio de Janeiro como destino de bens móveis orientais, fruto desse comércio, pois sabia-se que o referido titular havida permanecido na corte no Brasil naquele tempo, onde morreu, aliás, em 1820, e onde nasceram os filhos, como o demonstra o retrato pintado na altura e que publicámos em $1999^{5}$. Aliás, o próprio conde da Ribeira Grande encomendou serviços de porcelana armoriada nesse período ${ }^{6}$, que possuem o mesmo desenho das armas presentes no referido biombo e que datarão da mesma época ${ }^{7}$.

Mostra-se perfeitamente provável que as personagens que viviam nesta nova corte dos Trópicos encomendassem para o Oriente, os objectos asiáticos de luxo que ainda marcavam, nesse período, o gosto das elites portuguesas. $\mathrm{E}$ os serviços de porcelana chinesa cumpriam adequadamente tais desideratos de estatuto social ${ }^{8}$. Este é o cenário em que Luís Inácio Xavier Palmeirim, figura grada do exército português ${ }^{9}$, chega ao Rio de Janeiro, após o final das guerras peninsulares. Aí permanecerá, crê-se, até cerca de 1821.

A gestão que este encomendante, e proprietário, faz dos seus acervos poder-se-ia classificar como cuidadosa, verificando-se controlos episódicos dos aparelhos de mesa, o que ocorre em 1 de Janeiro de 1827, em 19 de Julho de 1834 e em 1 de Janeiro de 1837. Em cada um dos serviços eram aferidas as quantidades de peças inicialmente existentes, as entretanto quebradas e as que foram restauradas.

\section{O SERVIÇO DE Pó DE PEDRA INGLÊs (I 8 I 5 )}

Já desde finais do século XVIII que os aparelhos de mesa ingleses figuravam entre as louças das famílias da nobreza e da burguesia em Portugal continental e nos Açores. Em Ponta Delgada, por exemplo, o inventário orfanológico de bens de Joaquim da Costa Barradas, administrador do tabaco da ilha de São Miguel, dos inícios do século XIX, indica a presença de um serviço de pó de pedra ornamentado com ramos e países a preto, provavelmente inglês, apresentando uma assinalável variedade tipológica de formas ${ }^{10}$.

${ }^{5}$ Sousa 1999:163.

${ }^{6}$ Castro 1987:204 e 209.

${ }^{7}$ Petisca 2009:96.

${ }^{8}$ A presença de serviços de mesa e de chá de porcelana chinesa é uma constante nos inventários das elites em Portugal continental e insular, como o demonstram as notícias com que nos fomos deparando ao longo dos anos. Vd., a este propósito, entre outros: Sousa 2002:97; Sousa 2013:23 e 47; Sousa 2014a:55 e 75; Sousa 2014b:10, 18 e 30.

${ }^{9}$ Costa 2005: 90-91.

${ }^{10}$ Sousa 2013:22-23 e 47. É possível que sejam ingleses os serviços referenciados em Sousa 2014b: 30-31, respeitantes à herança de António Francisco Taveira Brum da Silveira (1828). 
O desenvolvimento de numerosos contactos comerciais do continente e das ilhas com Inglaterra favoreceu estas transacções e a consequente remessa de serviços ingleses, designadamente de pó de pedra ${ }^{11}$. A escala desta presença não é ainda perceptível, por ser necessário o levantamento de um maior número de fontes que nos esclareça de forma mais apurada sobre o real impacto da existência destes serviços, à semelhança do que sucederá mais tarde com as porcelanas francesas, tanto em Portugal como no Brasil ${ }^{12}$.

Neste presente caso (quadro I), que orçou em $66 \$ 000$ réis, as peças existentes ultrapassam as quatrocentas unidades, concentradas em grande número de pratos (sopeiros, ladeiros e de sobremesa), que totalizam cerca de 275 exemplares. As tipologias de maior dimensão, as terrinas para sopa, eram em número de cinco, sendo em maior quantidade (8) as destinadas ao serviço de caldos. Havia, ainda, pratos cobertos, tudo acompanhado pelos respectivos pratos. Para retirar os alimentos, as fábricas inglesas dispunham de colheres de pó de pedra, neste caso em número de 13, coincidente com as terrinas existentes.

Quanto às travessas, a maior complexidade dos usos da mesa fazia variar as suas dimensões em onze diferentes tamanhos, entre rombos e ovais, o que fornece uma ideia da variedade dos diversos volumes. A elas se vinha juntar a travessa para o peixe, com o seu ralo, e acompanhada de pés.

Os destinos alimentares ou condimentos especificam outros objectos, como os pratinhos de conserva, o prato para pudim, com pé, a saladeira e os saleiros.

No controlo das existências efectuado por Luís Inácio Xavier Palmeirim, em 1 de Janeiro de 1827, encontravam-se partidas 64 peças, tendo sido concertadas duas, pelo que se pode considerar que o serviço, atendendo ao seu uso em cerca de doze anos, estaria então com 340 peças, ou seja, aproximadamente $75 \%$ da sua dimensão inicial. Atendendo ao que pudemos já verificar em muitos serviços de mesa ingleses com que nos deparámos, a não ser que a família tivesse reservado o uso a poucas ocasiões ao longo da sua diatribe histórica, os conjuntos surgem com muitas falhas face à sua constituição original, facto que se vai acentuando com o decurso do tempo.

\section{O SERViço AZUl E branco (i 8 I 7 ), provavelmente de porcelana CHINESA}

Palmeirim deixou notícia de que era detentor de um outro serviço, adquirido em Julho de 1817, ou seja, um ano depois do referenciado conjunto de pó de pedra inglês. Tal facto representa a necessidade de um outro aparato

${ }^{11}$ Como é perceptível através do conhecimento dos acervos particulares da ilha de São Miguel e dos exemplares da ilha Terceira, revelados por Martins 1996.

12 Athayde 2000. 
no quotidiano que o seu posto de marechal de campo e tenente-general no Rio de Janeiro exigiam ${ }^{13}$, ou simplesmente a oportunidade de possuir um serviço, neste caso em tonalidades azul e branca. Os valores do seu custo não surgem referenciados na documentação existente, ao invés do que sucede com o serviço adquirido em 1815, mencionado supra, e do de porcelana chinesa mandado vir de Macau, a que aludiremos no ponto seguinte, encomenda datada também de 1817, mais precisamente de Agosto.

Este aparelho de mesa (quadro II) de cerâmica azul e branca - a origem, o material cerâmico e os motivos decorativos não são claramente especificados - apresenta-se menos complexo em diversidade tipológica, mas maior em quantidade (150 exemplares) que o conjunto anterior. Ao todo, dispunha, inicialmente, de 554 peças (e suas partes, pois as tampas e pratos são contabilizados individualmente). Salienta-se, neste contexto, o imenso número de pratos (de sopa, ladeiros e de sobremesa), que totaliza quase 400 objectos. Compunham-no, também, terrinas de maiores e menores dimensões, para além de molheiras e saladeiras, tipologias que não surgem identificadas no serviço inglês com risca escarlate. Referenciam-se pratos cobertos quadrados e ovais, bem como travessas de distintos tamanhos não especificados -, e pratos redondos côncavos. Acresce a estas tipologias um número assinalável (16) de saleiros e pimenteiros, fundamentais para o condimento dos alimentos.

O grau de deterioração do conjunto, em menos de 10 anos, foi significativo, perdendo-se mais de 200 peças e havendo que restaurar 11. Pela monumentalidade das existências iniciais, deveria ter sido usado com intensidade. Partiu-se uma grande quantidade de pratos de guardanapo - ou ladeiros - e de sopa, ficando muito desfalcados, em termos proporcionais, os pratos côncavos e chatos destinados aos doces. Outras tipologias particularmente afectadas pelas perdas foram a das travessas e a dos saleiros e pimenteiros, reduzidos a cerca de $2 / 3$ dos exemplares.

Em Junho de 1829 volta a haver nova contagem (quadro II) $)^{14}$, verificando-se perdas consideráveis, sobretudo nos pratos. O uso do aparelho, a que se vinham juntar as numerosas viagens a que a sua condição e militar e os cargos que ocupou determinavam, pode ter ocasionado a diminuição do serviço. Por outro lado, regista-se a aquisição de peças, designadamente de saladeiras e de travessas, esta última em número mais significativo ${ }^{15}$.

${ }^{13}$ Baena 1991: 451.

${ }^{14}$ Este registo surge realizado a lápis, aproveitando a contagem de 1827.

${ }^{15}$ Entre os papéis deste núcleo encontram-se novos registos, que pensamos poderem ser deste serviço, nomeadamente os controlos de existências efectuados em 1834 e 1837. Tais assentos referem expressamente que se trata de um serviço de porcelana azul e branca da China. 


\section{O Serviço de LOUÇA DA ChinA (I8I 7/I 819 E I 820/I 822)}

É no que concerne ao serviço de porcelana chinesa encomendada em Macau em duas fases, entre 1817 e 1820, que a documentação relacionada com os bens móveis de Luís Inácio Xavier Palmeirim adquire um interesse redobrado, pelo tipo de informações de contextualização que possui.

Em Agosto de 1817, o militar mandou vir de Macau, através de Sebastião Lopes Ramos, um serviço de mesa (fig. 4) decorado a verde e ouro, para o qual determinou certas precauções formais e estilísticas, que actualmente constituem indicações importantes para o reconhecimento da forma como se processava a encomenda deste tipo de peças (vd. anexo documental, doc.

1). Neste processo, o desenho de motivos decorativos ou de algumas peças especiais adquire particular significado. A acompanhar o pedido da remessa tipológica, foram expedidos para aquele interposto comercial na China, sob domínio português, uma tarja pintada, para servir de modelo à ornamentação da terrina, e um desenho de salva de pé, destinada aos pratos de queijo (fig.

5). Seguiu, igualmente, uma tampa de terrina sopeira e uma terrina para molhos, colher e travessa, que serviriam de modelo para a execução dessas tipologias. E, em jeito de conclusão do documento, reforçam-se as determinações, salientando que o "serviço deve ser da melhor louça que se possa fazer recomendando quando fizer a encomenda que o ouro seja fino, e que vá ao forno, para que não perca com facilidade, a folhage verde recomendo muito boa cor, assim como nos bons feitios das pessas". O serviço de porcelana deveria ter monograma ou qualquer outro tipo de marca, pois as indicações para as novas peças, encomendadas em 1820, aludem à presença da marca, de acordo com um prato que, nessa segunda fase, seguiu para modelo.

O aparelho de mesa foi alvo de duas fases de encomenda; uma, como se disse supra, realizada em Agosto de 1817 e que chegou em 1 de Outubro de 1819 , constituindo o corpo central do conjunto; a segunda, meses depois, em 12 de Fevereiro de 1820, que o proprietário receberia em 1822. Vejamos que tipologias caracterizaram ambas as encomendas, aferindo o que se mandou fazer e aquilo que, efectivamente, acabou por chegar.

A primeira leva (vd. anexo documental, doc. 1) compreendeu três terrinas para a sopa (12 polegadas), de maiores dimensões. $O$ militar recomendou que se fizesse "o mais elegante que se tenha feito", seguindo o modelo ornamental apresentado por tarja que seguiu junto, em verde vivo e com recurso a ouro fino. O pomo da pega deveria ter uma folhagem semelhante a uma tampa enviada para amostra.

Viriam quatro terrinas pequenas (6 polegadas) para molho (ou para caldo, como também as descreve), com prato e colher. Ainda neste tipo de peças cobertas, far-se-ia oito pratos cobertos quadrados, sendo metade de 10 polegadas e outra metade de 9 . Nas listagens futuras, os de 9 polegadas 
não surgem (quadro $V$ ), possivelmente por parecerem desnecessários, visto que apenas variavam uma polegada dos outros.

Para o queijo, deveriam vir dois pratos redondos, de 12 polegadas, em forma de salva de pé médio, como o desenho que seguiu em papel. Não temos indicação da sua execução, o mesmo sucedendo com quatro pratos fundos para forno e sem tampa, e quatro vasos de "bom modello tambem irmãos em pintura" (quadro III).

Existia um conjunto de cinco travessas, em igual número por cada tamanho (10, 12, 13, 16 e 18 polegadas) e, destinado ao serviço do peixe, duas travessas de ralo com 15 polegadas. A de maiores dimensões, com 20 polegadas, destinava-se ao leitão, mandando vir três exemplares.

A funcionalidade alimentar das tipologias encontra-se bem expressa com as indicações da descrição; eram as saladeiras - de matriz inglesa -, os cestos de fruta, de que se mandaram vir quatro na primeira leva, reforçados por mais oito na segunda, possivelmente porque se assinalam diversas peças partidas. A eles se vêm juntar as manteigueiras e os saleiros.

O grande núcleo, como habitual, diz respeito aos pratos, sobretudo os de guardanapo (96), os de sopa (36) e os de sobremesa (90), apresentando-se estes de três tamanhos distintos, e uns deles fundos ou côncavos.

Sentindo a necessidade de complementar esta primeira remessa, o militar decidiu, em 1820, e como se disse supra, complementar o serviço (fig. 6), mandando vir 9 pratos para tortas, pudins e outras massas, com diferentes tamanhos. Contudo, apenas se registam 5 pratos redondos para pudim. Tigelas com pratos para caldos e novos cestos de fruta - ditos à inglesa - fizeram parte, ainda, deste reforço de peças então encomendadas (quadro IV).

Segundo se torna perceptível nos escritos de Palmeirim, o conjunto nunca teria servido (quadro III), pois se a primeira remessa apanhou o militar nos seus últimos tempos de Brasil, a segunda foi enviada estando o mesmo já nomeado, por decreto de 25 de Abril de 1821, governador e capitão-general das ilhas de Cabo Verde ${ }^{16}$.

Outro aspecto interessante em relação a este serviço prende-se com os gastos despendidos por Luís Inácio Xavier Palmeirim com as duas encomendas, e as especificidades de despesas envolvidas. A primeira remessa, e principal, partiu da verba inicial de $258 \$ 000$ réis, custo do aparelho de mesa na origem. O câmbio para patacas onerou-o em $22 \$ 940$, e a estas despesas vieram juntar-se outras, designadamente o seguro ( $90 \$ 000$ rs.), o frete (90\$000 rs.), a comissão (12\$400 rs.) e os direitos na alfândega (30\$000 réis). Portanto, a verba inicial, de $258 \$ 000$ rs., veio a transformar-se em $503 \$ 640$ réis, a que acresceu a segunda encomenda, de que somente existe a notícia de que atingiu os $29 \$ 100$ réis, num custo total que ascendeu a $532 \$ 740$ réis.

\footnotetext{
${ }^{16}$ Baena 1991: 451.
} 


\section{OUTRAS louças PARA CHÁ, CAFÉ E CHOCOLATE; VIDROS E CRISTAIS}

Indispensável, já desde Setecentos, aos requintes do serviço das bebidas consideradas até então exóticas, assinala-se a presença, entre os bens móveis de Luís Inácio Xavier Palmeirim, de conjuntos e de peças individuais, formando, por vezes, grupos alargados. Tal como nos acervos das elites da época, imperavam as louças de porcelana chinesa, dita da Índia, e também as peças de pó de pedra inglesas e francesas. No entanto, tal como se pode aferir pela ausência de estudos específicos, é-nos impossível perscrutar, com a investigação até hoje realizada, quais as importâncias relativas destas cerâmicas de natureza diferenciada.

Entre as louças de Palmeirim, destaca-se um serviço de chá de porcelana chinesa composto por bule, açucareiro com tampa e prato, leiteira, tigela de lavar xícaras e dois pratos para fatias. Para chocolate, chá e café, dispunha de xícaras de distintos tipos: para chá e café, xícaras escarlates; para café e chocolate, xícaras brancas e douradas, e, em porcelana da Índia, xícaras para chá, brancas e ornamentadas com ramos. Outras xícaras eram brancas com riscas encarnadas e azuis e outras brancas e roxas douradas, o que demonstra a variedade de que se compunha o acervo deste militar. Entre 1834 e 1837, dados para os quais existem elementos de registo, partiram-se ou desapareceram, em geral, poucos exemplares.

Entre 1834 e 1837 percebe-se, pelos seus registos meticulosos, que Palmeirim adquiriu um serviço de chá de louça francesa, composto por bule, leiteira, açucareiro e taça de lavar as xícaras e ainda 12 xícaras acompanhadas dos respectivos pires. A documentação é omissa quanto a pormenores decorativos do conjunto.

Em relação a vidros e cristais, as descrições são relativamente exíguas, com a listagem a elencar os objectos essenciais para acompanhar as louças atrás analisadas (e outras que, por economia de espaço, não referenciamos). Assinala-se a presença de garrafas lapidadas para vinho e água, bem como diversos copos para água, vinho e licores; tigelas verdes para lavar a boca, um galheteiro de casquinha com quatro vidros e outro com duas galhetas, compoteiras lapidadas com tampa e prato, e uma mostardeira compunham o acervo. A estas tipologias, e denotando a referência no serviço de bebidas espirituosas, soma-se a descrição de uma garrafinha de licor e, sobretudo, de uma roda para licores com 3 garrafas e 8 copos.

\section{Conclusão}

Os diversos serviços de louça de que era possuidor o tenente-general Luís Inácio Xavier Palmeirim revelam as preocupações em requintar gestos e atitudes à mesa, no primeiro quartel do século XIX, por entre Brasil e Portugal. 
No cenário de uma Corte nos Trópicos, a posse de serviços ingleses e de porcelana chinesa - dita louça da Índia -, constituídos por algumas centenas de peças, representava, certamente, um factor de forte expressão social.

A percepção das tipologias que formavam os aparelhos de mesa pode ser atestada através das múltiplas referências indicadas neste estudo, apoiadas em quadros de sistematização e no anexo documental, de forma a fornecer outros dados aos estudiosos da porcelana. As indicações documentais evidenciam, igualmente, a designação funcional de algumas tipologias, apontando para os alimentos e condimentos que serviam. Outras vezes, mas nem sempre, são indicados pormenores ornamentais, que se enquadram nas decorações da época, em geral, de gosto mais depurado, provavelmente de um neoclassicismo em fase já de estilização.

A minúcia descritiva e sistemática que caracteriza alguns dos espécimes, fruto das preocupações de registo do proprietário (anos de 1827, 1829, 1834 e 1837), permite considerar esta fonte como referencial, sobretudo a respeitante à encomenda faseada, em 1817 e 1820, de um aparelho de mesa decorado a verde e ouro. E os pormenores do envio do Rio de Janeiro para Macau de formas e motivos decorativos, de modo a seguirem escrupulosamente o pretendido pelo militar português, testemunham o modus faciendi deste tipo de encomendas efectuadas na China, referentes a produtos de luxo, entre os quais se encontrava, ainda nesta época, a porcelana.

\section{Fontes e Bibliografia}

\section{Fontes electrónicas}

http://www.familiasdeleiria.com/p373.htm (18/07/2015).

\section{Fontes manuscritas}

Porto. Arquivo Particular, Dossier Palmeirim, documentos referentes a louças, vidros, pratas e jóias pertencentes ao tenente-general Luís Inácio Xavier Palmeirim.

\section{Bibliografia}

Athayde, S. M. de (2000), Louça histórica: Museu de Arte da Babia, Museu de Arte da Bahia, Salvador, Bahia.

Baena, V. de S. de (1882), Ascendentes e alianças do Ill.mo e Ex.mo Sr. General Palmeirim, Tipografia de Mattos Moreira \& Cardosos, Lisboa.

Baena, V. de S. de (1991, 2. a ed.), Archivo heraldico-genealogico, Fernando Santos, Luís Wenceslau Barroso, Rodrigo Faria de Castro, [S. 1].

Castro, N. de (1987), A porcelana chinesa e os brasões do Império, Civilização Editora, [s. 1.].

Costa, A. J. P. da (ed.) (2005), Os generais do exército português, Biblioteca do Exército, Lisboa, vol. 2, tomo 1. 
Martins, F. E. de O. (1996), Louça inglesa nos Açores, [s. n.], Angra do Heroísmo.

Petisca, M.J. dos S. N. (2009), A laca de Cantão: um estudo sobre biombos chineses de exportação nos séculos XVIII e XIX, [s. n.], Dissertação de Mestrado em Artes Decorativas apresentada à Escola das Artes da Universidade Católica Portuguesa, Lisboa.

Petisca, M.J. (2010),"A laca de Cantão: um estudo sobre biombos chineses de exportação nos séculos XVIII e XIX", Revista de Artes Decorativas, 4: 65-100.

Sousa, G. de V e (1999), A joalharia em Portugal: 1750-1825, Civilização Editora, Porto.

Sousa, G. de V e (2002), Artes da mesa em Portugal: do século XVIII ao século XXI, Ed. Maria João Oliveira, Porto.

Sousa, G. de V e (2013),"Reflexões em torno das fontes para os ambientes e as Artes Decorativas: a propósito dos bens móveis de um administrador do tabaco da ilha de São Miguel", in Gonçalo de Vasconcelos e Sousa (ed.), Matrizes da investigação em Artes Decorativas V, UCE-Porto, CITAR, Porto: 11-76.

Sousa, G. de V e (2014a), Fontes para as Artes Decorativas nos Açores III, UCE-Porto, CITAR, Porto.

Sousa, G. de V e (2014b), Fontes para as Artes Decorativas nos Açores IV, UCE-Porto, CITAR, Porto.

\section{Anexo documental}

\section{Documento 1}

1817, Agosto, 6 - Rio de Janeiro.

Especificações da encomenda e gastos com um serviço de porcelana chinesa encomendado em Macau pelo tenente-general Luis Inácio Xavier Palmeirim.

Arquivo Particular, Dossier Palmeirim.

"Nota para o aparelho de meza que encommendo ao Sr. V.F. Sp. ${ }^{\circ}$ para me mandar vir de Macau no navio Maria 1. ${ }^{a}$, ou quem suas vezes fizer de baixo da marca LIXP ou letras ao mesmo a saber

3 Terrinas para sopa $=\mathrm{o}$ mais elegante que se tenha feito, tendo a mesma tarja que a do risco do papel, em verde bem vivo, e bom ouro, e o mesmo se deve observar na tampa, e no sitio aonde se pega deve ter huma folhage tambem verde irmãas da da tampa que vai por amostra, de 12 pollegadas

4 ditas pequenas para molho como a que vai por amostra com prato e colher de 6 pollegadas

4 Pratos quadrados cobertos de 9 pollegadas

4 Ditos ditos......10 [polegadas]

2 Pratos para queijo redondos de 12 pollegadas - feitio de salva [de pé médio, com desenho no documento]

4 Pratos fundos para forno, sem tampa de 10 pollegadas

2 Pratos para peixe, que o ralo tenha 15 pollegadas 
5 Jogos de pratos traveços, de 5 em jogo, tendo o menor 10 pollegadas, o $2^{\circ}$ 12 , o $3 .^{\circ} 14-$ o $4 .^{\circ} 16$ - o $5 .^{\circ} 18$ de comprido.

3 Pratos de 20 pollegadas para leitão

2 Seladeiras quadradas inglezas.

4 Cestos para fruta com seus competentes pratos.

4 Manteigueiras de bico com seu prato.

4 Salleiros da figura da amostra.

36 Pratos para sopa de 9 pollegadas

96 Ditos de goardanapo dito ditas

48 Pratos de sobremeza de 8 pollegadas

36 Ditos 7 ditas

6 Ditos fundos 6 ditas

4 Vazos de bom modello tambem irmãos em pintura

Todo este serviço deve ser da melhor louça que se possa fazer recomendado quando fizer a encomenda que o ouro seja fino, e que vá ao forno, para que não perca com facilidade, a folhage verde recomendo muito boa cor, assim como nos bons feitios das pessas Rio 6 de Agosto de 1817 [f. 1v.]

Custo da Louça

Capital $258 \$ 000$

Cambio a patacas a 70 rs. cada huma $22 \$ 940^{17}$

Risco $^{18}$ a 35 por 100 do capital $90 \$ 300$

Frete $90 \$ 000$

Comissão $12 \$ 400$

Direitos na Alfandega 30\$000 $503 \$ 640$

Custo da 2. a encomenda $29 \$ 100$ $532 \$ 740 "$

\footnotetext{
${ }^{17}$ Palavra emendada.

${ }^{18}$ Palavra emendada.
} 